\title{
Medial gastrocnemius volume and echo-intensity after botulinum neurotoxin A interventions in children with spastic cerebral palsy
}

\author{
SIMON-HENRI SCHLESS ${ }^{1,2}$ (D) | FRANCESCO CENNI ${ }^{2,3}$ | LYNN BAR-ON $^{1,4}$ | BRITTA HANSSEN $^{1,2}$ | \\ BARBARA KALKMAN ${ }^{5}$ (D) | THOMAS 0'BRIEN ${ }^{5}$ | ERWIN AERTBELIËN ${ }^{3}$ | ANJA VAN CAMPENHOUT'2,6 (D) | \\ GUY MOLENAERS ${ }^{6,7}$ | KAAT DESLOOVERE ${ }^{1,2}$
}

\begin{abstract}
1 Department of Rehabilitation Sciences, KU Leuven, Leuven; 2 Clinical Motion Analysis Laboratory, University Hospitals Leuven, Pellenberg; 3 Department of Mechanical Engineering, KU Leuven, Leuven, Belgium. 4 Department of Rehabilitation Medicine, Amsterdam Movement Sciences, Amsterdam UMC, Vrije Universiteit Amsterdam, Amsterdam, the Netherlands. 5 Research Institute of Sport and Exercise Science, Liverpool John Moores University, Liverpool, UK. 6 Department of Orthopaedic Medicine, KU Leuven, Leuven; 7 Department of Development and Regeneration, KU Leuven, Leuven, Belgium.
\end{abstract}

Correspondence to Simon-Henri Schless at Department of Rehabilitation Sciences, KU Leuven, Weligerveld 1, 3212 Pellenberg, Belgium. E-mail: simonhenri.schless@kuleuven.be

\section{PUBLICATION DATA}

Accepted for publication 21st August 2018. Published online 15th October 2018.

[Correction added on 23 October 2018 after first publication: reference 24 has been added and the ethical commission number has been corrected.]
AIM This cross-sectional investigation evaluated whether recurrent botulinum neurotoxin A (BoNT-A) interventions to the medial gastrocnemius have an influence on muscle morphology, beyond Gross Motor Function Classification System (GMFCS) level. METHOD A cohort of typically developing children ( $n=67 ; 43$ males, 24 females; median age 9y $11 \mathrm{mo}$ [range $7 y$ 10mo-11y $6 \mathrm{mo}$ ]), a cohort of children with spastic cerebral palsy (CP) naive to BoNT-A interventions (No-BoNT-A; $n=19$; 10 males, nine females; median age 9y $3 \mathrm{mo}$ [range $8 \mathrm{y} 5 \mathrm{mo}-10 \mathrm{y} 10 \mathrm{mo}$ ]) and a cohort of children with spastic CP with a minimum of three recurrent BoNT-A interventions to the medial gastrocnemius (BoNT-A; $n=19 ; 13$ males, six females; median age 9 y $8 \mathrm{mo}$ [range $7 \mathrm{y} 3 \mathrm{mo}-10 \mathrm{y} 7 \mathrm{mo}$ ]) were recruited. Three-dimensional freehand ultrasound was used to estimate medial gastrocnemius volume normalized to body mass and echo-intensity.

RESULTS Normalized medial gastrocnemius volume and echo-intensity significantly differed between the two spastic CP cohorts $(p \leq 0.05)$, with the BoNT-A cohort having larger alterations. Associations between normalized medial gastrocnemius volume and echointensity were highest in the No-BoNT-A cohort, followed by the BoNT-A cohort. Multiple regression analyses revealed that both GMFCS level and BoNT-A intervention history were significantly associated with smaller normalized medial gastrocnemius volume and higher echo-intensity.

INTERPRETATION Recurrent BoNT-A interventions may induce alterations to medial gastrocnemius volume and echo-intensity beyond the natural history of the spastic $\mathrm{CP}$ pathology.
Muscles are the motor components of the body. Their rate of growth in the early years of life is crucial for achieving developmental milestones, such as crawling, standing, and walking. The force-generating capabilities of a muscle are largely dependent on its gross-morphological properties, such as volume. In children with spastic cerebral palsy (CP), fewer satellite cells, over-lengthened sarcomeres, and abnormal motor unit recruitment and activation characterize the underlying pathophysiology of muscle growth and joint contractures. ${ }^{1,2}$ Consequently, deficits in medial gastrocnemius growth have been reported, ${ }^{3-5}$ which affects the important power generation function of the muscle during walking. ${ }^{6}$ To confound matters, magnetic resonance imaging (MRI) has revealed adipose tissue replacing contractile tissue in the lower limb muscles of children and adolescents with bilateral spastic CP. ${ }^{7,8}$ This was corroborated using B-mode ultrasound, where the medial gastrocnemius appeared hypoechoic in comparison to typically developing peers. ${ }^{9,10}$ Two of these investigations also identified that the extent of changes within the muscle was associated with Gross Motor Function Classification System (GMFCS) level, ${ }^{8,9}$ as was muscle volume, ${ }^{4}$ inferring that muscle activation and level of functional ability play an important role in these alterations. It is, therefore, likely that there will be a high association between the volume and echo-intensity of the medial gastrocnemius in individuals with spastic CP.

The use of botulinum neurotoxin A (BoNT-A) is a common treatment modality in children with spastic CP, targeting the hyperactive stretch reflex. ${ }^{11}$ Short-term chemo-denervation at the presynaptic membrane, combined with serial casting, and physiotherapy, has been shown to improve gait function. ${ }^{12}$ Its use is not without concern, as discussed in a review on muscle deformity in children with 
spastic CP. ${ }^{13}$ Attempts to address the veracity of these concerns have been undertaken in several longitudinal investigations, where medial gastrocnemius volume was evaluated after BoNT-A interventions. A reduction in volume was reported 5 weeks postinfiltration, ${ }^{14}$ but a 6 -month follow-up with a targeted strength training protocol revealed eventual gains in both volume and strength. ${ }^{15}$ A long-term investigation 1 year after intervention found absolute medial gastrocnemius volume had increased in two cohorts of BoNT-Anaive children with spastic CP. ${ }^{16}$ However, the use of absolute volume, instead of a normalized parameter (not taking the interim $1 \mathrm{y}$ of growth into consideration) might have biased the results. Based on their reported data, normalizing mean medial gastrocnemius volume to mean body mass revealed a mean decrease from 1.70 to $1.62 \mathrm{~mL} / \mathrm{kg}$ in one cohort, and a mean increase from 1.54 to $1.56 \mathrm{~mL} / \mathrm{kg}$ in the other cohort. ${ }^{16}$ This strengthens the notion that BoNT-A interventions may lead to reduced medial gastrocnemius volume in the long-term.

These insightful findings regarding the use of BoNT-A are of interest to the wider clinical community, but there are some limitations to consider. First, in two of the investigations, ${ }^{14,15}$ the cohorts had received an unspecified number of previous BoNT-A interventions, providing a challenge to differentiate the influence of previous BoNTA interventions from the natural history of the spastic CP pathology. Second, muscle volume does not provide insight into alterations to the intramuscular composition, where a high recurrence of BoNT-A infiltrations, or BoNT-A infiltrations delivered with a short interval was associated with neurogenic atrophy. ${ }^{17}$ In addition, the number of BoNT-A infiltrations to the medial gastrocnemius was significantly associated with type- 1 fibre loss and type- 2 fibre predominance, which may impair long-term muscle function. ${ }^{17}$ Therefore, future investigations evaluating the influence of BoNT-A interventions should also consider alterations to both contractile (myofibers) and non-contractile (adipose/ connective tissue) tissue within the injected muscle.

Three-dimensional freehand ultrasonography is a staticcondition measurement modality that enables anatomical regions to be reconstructed in three-dimensions. It consists of a B-mode ultrasound and motion-tracking system, where the spatial coordinates of reflective markers rigidly affixed to the ultrasound probe are recorded for each acquired image. ${ }^{18}$ It requires minimal acquisition time, which is favourable in measurements with younger children. Using three-dimensional freehand ultrasonography, alterations to medial gastrocnemius volume and echointensity in children with spastic CP were reported. ${ }^{10,19,20}$ When visualising healthy muscles, non-contractile properties such as tendons and adipose tissue appear lighter (hyperechoic), whilst fluid and bones appear darker (hypoechoic). A biopsy analysis revealed a high association between echo-intensity and the proportion of fibrous tissue in the extracted sample, ${ }^{21}$ whilst MRI revealed high associations between echo-intensity of the medial gastrocnemius with the quantity of intramuscular adipose tissue. ${ }^{22}$ These

\section{What this paper adds}

- In spastic cerebral palsy, medial gastrocnemius volumes are smaller and echo-intensities higher compared with typical development.

- Alterations after botulinum neurotoxin A intervention (BoNT-A) are larger than in no BoNT-A intervention.

- Gross Motor Function Classification System level and BoNT-A history significantly associate with medial gastrocnemius and echo-intensity alterations.

findings suggest that echo-intensity can be used as an indirect quantification of alterations to the properties within a muscle.

This investigation explored the influence of BoNT-A interventions on the medial gastrocnemius volume and echo-intensity in individuals with spastic CP. A cross-sectional design was employed, where two spastic CP cohorts were identified: (1) participants with a minimum of three BoNT-A interventions (BoNT-A cohort) and (2) participants naive to BoNT-A interventions (No-BoNT-A cohort). A matched typically developing control cohort was also identified.

The first aim was to compare normalized medial gastrocnemius volumes and echo-intensities between the two spastic CP cohorts, and compare with the typically developing cohort. The hypothesis stated that both spastic CP cohorts had significantly smaller medial gastrocnemius volumes and higher echo-intensities with respect to the typically developing cohort, whilst the alterations in the BoNT-A cohort would be significantly greater with respect to the NoBoNT-A cohort. The second aim was to explore the association between medial gastrocnemius volume and echointensity in all three cohorts. The hypothesis stated that there would be no meaningful association in the typically developing cohort, but strong negative associations in the spastic CP cohorts. The third aim was to explore if BoNTA intervention history was significantly associated with smaller medial gastrocnemius volume and higher echointensity, in addition to GMFCS level. The hypothesis stated that both GMFCS level and BoNT-A intervention history would be significantly associated with smaller medial gastrocnemius volume and higher echo-intensity.

\section{METHOD \\ Participants}

Data collection was performed as part of an ongoing research project (Muscle Morphology and Function in Spastic Cerebral Palsy), where typically developing children and adolescents, as well as those diagnosed with spastic $\mathrm{CP}$, were recruited through the clinical motion analysis laboratory at the University Hospital of Leuven between January 2015 and September 2017. The initial diagnosis of spastic $\mathrm{CP}$ was confirmed by a neuropaediatrician, based on Brain MRI and clinical examination. To minimize bias and ensure appropriate matching of two spastic CP cohorts, the following inclusion criteria were applied to all previously acquired data: (1) age between 5 years and 16 years; (2) in GMFCS level I or II; (3) no previous orthopaedic or neurological surgery; and (4) naive to BoNT-A interventions or at least 6 months after a third or more recurrent BoNT-A 
intervention. Using this retrospective analysis, 42 children and adolescents with spastic CP that fulfilled the criteria were identified. BoNT-A and No-BoNT-A cohorts were then defined, matched in order of GMFCS level, topographical paresis, body mass, and age. This resulted in two groups of 19 participants, with the remaining four participants excluded. The earliest clinical examination for each participant was also reviewed to ensure comparable baseline clinical characteristics for joint range of motion, spasticity, and strength at the ankle (Table SI, online supporting information). The BoNT-A cohort had a median of five previous interventions (interquartile range [IQR] 3-6), with a median frequency of 12 months between interventions (IQR 10-16). All 38 participants were under the same multidisciplinary management, whilst the BoNT-A cohort all followed the same after BoNT-A treatment protocol, consisting of serial casting and physiotherapy. ${ }^{23}$ An overview of the quantity and timing of the BoNT-A interventions can be found in Figure S1 (online supporting information). A typically developing cohort was also defined and matched with respect to body mass and age, which resulted in 67 participants (Table I). The experimental protocol was approved by the Ethical-Committee of the University Hospitals of Leuven (s57384), whilst written informed consent was acquired from all parents/guardians and children over the age of 12 years.

\section{Instrumentation}

A three-dimensional freehand ultrasonography method was utilized for this investigation. ${ }^{18}$ This consisted of a Telemed-Echoblaster 128 Ext-1Z B-mode ultrasound system with a $5.9 \mathrm{~cm} 10 \mathrm{MHz}$ linear US probe (HL9.0/60/ 128Z) (Telemed Medical Systems, Milan, Italy) and an OptiTrack V120:Trio motion-tracking system with three fixed optical cameras (NaturalPoint, Corvallis, OR, USA). As echo-intensity is influenced by the ultrasound acquisition settings, care was taken to ensure they remained the same for all of the acquisitions (frequency, $10 \mathrm{MHz}$; depth, $5 \mathrm{~cm}$; focus, $1.8-2.8 \mathrm{~cm}$; gain, $46 \%$; dynamic range, $44 \mathrm{~dB}$ and unaltered time-gain compensation), whilst images were recorded at $30 \mathrm{~Hz}$. Due to a hardware change during the course of the data collection, a validated conversion equation ${ }^{24}$ was applied to the echointensity data for 33 of the 105 participants. The motion- tracking system has a $1 \mathrm{~mm}$ spatial resolution, and images were recorded at $120 \mathrm{~Hz}$. To acquire synchronized data, a signal trigger was utilized. ${ }^{18}$

\section{Acquisition}

For each participant with spastic CP, the most affected leg was measured according to their most recent clinical examination, whilst a coin-flip determined the measured leg in the typically developing cohort. Age and body mass were recorded for each participant. In prone position, a triangular cushion was placed under the lower leg to provide approximately $25^{\circ}$ of knee flexion, and a cushioned belt was strapped over the thigh to prevent movement of the leg (Fig. 1). Two physiotherapists (SHS and LB) experienced with three-dimensional freehand ultrasonography and visual identification of the medial gastrocnemius acquired all of the data, using sufficient gel to avoid excess pressure on the leg. Care was taken to hold the ultrasound probe perpendicular to the deep aponeurosis of the medial gastrocnemius throughout the acquisition, enhancing the visibility of the muscle border and minimizing erroneous echoes. The ultrasound probe was moved in a transverse orientation over the condyles of the knee, distally along the medial gastrocnemius until the end of the calcaneus. In cases of visually detected muscle contraction or movement of the leg, the acquisition was repeated. Two acquisitions were acquired for each participant.

\section{Processing}

Three-dimensional reconstructions were created using a custom-made software package, ${ }^{18}$ and processed using Horos, a free open source medical image viewer (www. horosproject.org). The same physiotherapist (SHS) performed all of the processing using the first of the two acquisitions. The medial gastrocnemius was defined from the inferior margin of the medial condyle of the tibia, until the most distal visible image of the medial gastrocnemius. ${ }^{25}$ Volume and echo-intensity were estimated by drawing equally spaced transverse plane segmentations along the inside of the muscle border, summing $10 \%$ of all the available ultrasound images of the medial gastrocnemius. An interpolation was applied to create segmentations in the remaining $90 \%$ of images. This reduced the time required to extract medial gastrocnemius volume and echo-

Table I: Overview of participant characteristics

\begin{tabular}{llcr}
\hline & TD $(n=67)$ & Spastic CP No-BoNT-A $(n=19)$ & Spastic CP BoNT-A $(n=19)$ \\
\cline { 2 - 4 } Cohorts & Median (IQR) & & $9: 3(8: 5-10: 10)$ \\
\hline Age $(y: m o)$ & $9: 11(7: 10-11: 6)$ & $9: 8(7: 3-10: 7)$ & $13 / 6$ \\
Sex M/F & $43 / 24$ & $10 / 9$ & $26.5(22.9-29.7)$ \\
Mass (kg) & $29.6(24.3-39.8)$ & $29(20.5-42)$ & $9 / 10$ \\
Topographic paresis, BL/UL & NA & $9 / 10$ & $13 / 6$ \\
GMFCS levels, I/II & NA & $13 / 6$ & \\
\hline
\end{tabular}

No-BoNT-A, cohort naive to previous botulinum neurotoxin A interventions; BoNT-A, cohort with a minimum of three previous BoNT-A interventions; CP, cerebral palsy; TD, typically developing; IQR, interquartile range; BL, bilateral; UL, unilateral; GMFCS, Gross Motor Function Classification System; NA, not applicable. 


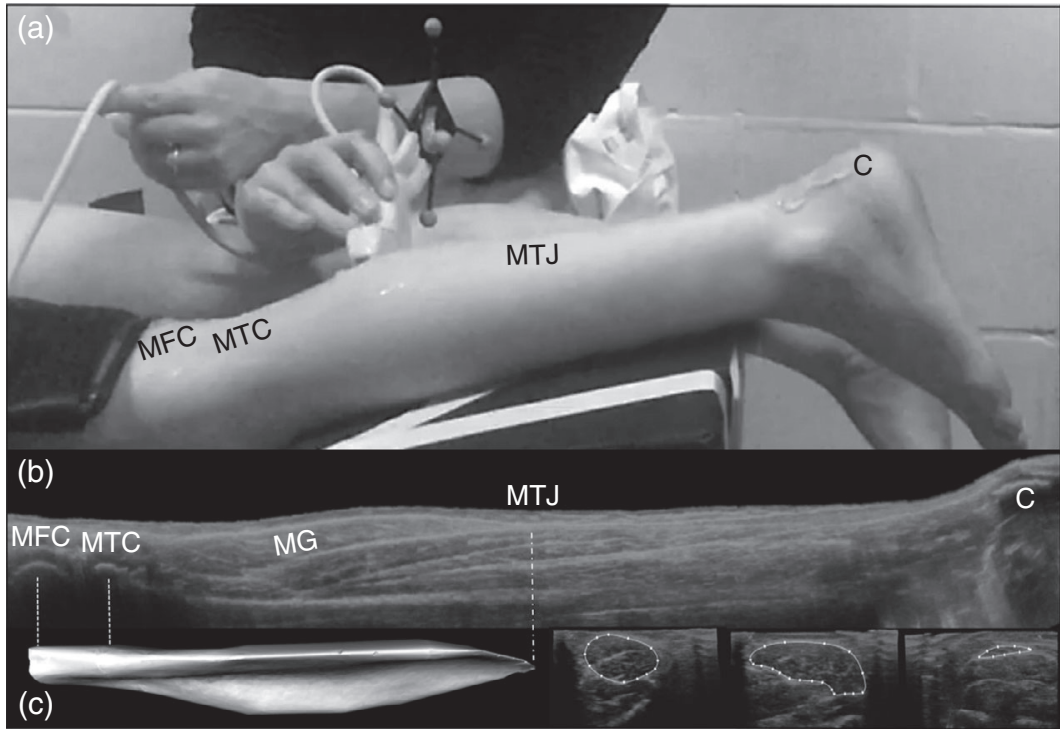

Figure 1: Three-dimensional freehand ultrasonography set-up, acquisition, and processing. (a) An example of the three-dimensional freehand ultrasonography measurement acquisition with the instrumented ultrasonography probe. (b) A sagittal plane image extracted from the three-dimensional reconstruction. (c) Examples of muscle border segmentations in the transverse plane images and the resulting interpolated three-dimensional reconstruction of the medial gastrocnemius. MFC, medial femoral condyle; MTC, medial tibial condyle; MG, medial gastrocnemius; MTJ, muscle-tendon junction; C, calcaneus.

intensity, whilst also maintaining sufficient reliability (standard error of measurement values for estimating medial gastrocnemius volume and echo-intensity are $2.6 \mathrm{~mL}$ and 3.3 values respectively). ${ }^{20}$ Medial gastrocnemius volume was reported in millilitres $(\mathrm{mL})$ and echo-intensity on an 8-bit greyscale (256 values). For the latter, black represented a value of 0 and white represented a value of 255 , with in-between values 254 shades of grey. To enable interparticipant comparisons, medial gastrocnemius volume was normalized to body mass and reported as $\mathrm{mL} / \mathrm{kg}^{3-5}$ An illustration of the three-dimensional acquisition and processing can be found in Figure 1.

\section{Statistical analysis}

Data were analysed in SPSS version 22 (SPSS, Inc., Chicago, IL, USA). Normal distribution of the primary outcome parameters was accepted by plotting the data and visually inspecting the symmetry of the histogram. In addition, the data was also reported as median and IQR, revealing the extent of skewness in each parameter. Equality of variance was assessed using Levene's test $(p \geq 0.05)$ and treated accordingly. The threshold for statistical significance was two-tailed. To determine if the spastic CP cohorts differed at the time of their earliest clinical examination, age, ankle dorsiflexion (with the knee extended), modified Ashworth score, modified Tardieu scale, and manual muscle testing of the plantar flexors were compared using an independent samples Mann-Whitney $U$ test $(p \leq 0.05)$. To answer the first hypothesis, a one-way analysis of variance and Tukey honestly significant difference post hoc test compared age, body mass, absolute and normalized medial gastrocnemius volume, and echo-intensity between the three cohorts. To answer the second hypothesis, a Pearson's correlation was used to determine the strength of the associations between echo-intensity and normalized medial gastrocnemius volume in the two spastic $\mathrm{CP}$ and typically developing cohorts $(0-0.2$, poor; $0.21-$ 0.4 , fair; $0.41-0.6$, moderate; $0.61-0.8$, good; and $0.81-1.0$, very good). ${ }^{26}$ To answer the third hypothesis, multiple regression analyses were performed on the combined spastic CP cohorts. Both GMFCS level and BoNT-A intervention history (No-BoNT-A cohort: group 0, BoNT-A cohort: group 1) were entered as independent variables to determine if they were both significantly associated with normalized medial gastrocnemius volume and echo-intensity. The adjusted $r^{2}$ and $p$-value of the model, and $p$-value of each independent variable was calculated.

\section{RESULTS}

The Mann-Whitney $U$ test revealed no significant difference in age, body mass, or outcome parameters between the two spastic CP cohorts at their earliest clinical examination, except for maximum ankle dorsiflexion $(p=0.030$; Table SI). The Tukey honestly significant difference post hoc test revealed no significant differences between the three cohorts for age $\left(F_{2,102}=0.023 ; p=0.977\right)$ or body mass $\left(F_{2,102}=1.237 ; p=0.295\right)$. Statistically significant differences were found for all the primary outcome parameters, except absolute medial gastrocnemius volume between the spastic CP cohorts (Table II). 
Table II: Overview and comparison of the primary outcome parameters between all three cohorts, and the associations between medial gastrocnemius (MG), mean echo-intensity, and normalized muscle volume

\begin{tabular}{|c|c|c|c|c|c|c|}
\hline \multicolumn{7}{|c|}{ Outcome parameters } \\
\hline & TD $(n=67)$ & $\begin{array}{l}\text { Spastic CP } \\
\text { No-BoNT-A }(n=19)\end{array}$ & $\begin{array}{l}\text { Spastic CP } \\
\text { BoNT-A }(n=19)\end{array}$ & $\begin{array}{l}\text { TD vs spastic } \\
\text { CP No-BoNT-A }\end{array}$ & $\begin{array}{l}\text { TD vs spastic } \\
\text { CP BoNT-A }\end{array}$ & $\begin{array}{l}\text { Spastic CP No-BoNT-A } \\
\text { vs spastic CP BoNT-A }\end{array}$ \\
\hline & \multicolumn{3}{|l|}{ Median (IQR) } & \multicolumn{3}{|c|}{ Independent samples $t$-test $(p \leq 0.05)$} \\
\hline $\begin{array}{l}\text { Echo-intensity } \\
(0-255)\end{array}$ & $99.8(93.6-106.5)$ & $117.1(110.7-121.2)$ & $124.9(120.6-132.9)$ & $\leq 0.001$ & $\leq 0.001$ & 0.004 \\
\hline MG volume (mL) & $62.0(49.7-81.8)$ & $44.4(33.7-58.9)$ & $31.5(25.3-44.0)$ & $=0.004$ & $\leq 0.001$ & 0.140 \\
\hline $\begin{array}{l}\text { Normalized MG } \\
\text { volume }(\mathrm{mL} / \mathrm{kg})\end{array}$ & $2.1(1.8-2.3)$ & $1.5(1.3-1.7)$ & $1.2(1.0-1.6)$ & $\leq 0.001$ & $\leq 0.001$ & 0.032 \\
\hline
\end{tabular}

Pearson correlation (echo-intensity vs normalized MG volume)

\begin{tabular}{lllc}
\hline & TD $(n=67)$ & Spastic CP No-BoNT-A $(n=19)$ & Spastic CP BoNT-A $(n=19)$ \\
\hline$r$ & -0.27 & -0.72 & -0.54 \\
$p$ (significance $\leq 0.05)$ & 0.025 & $\leq 0.001$ & 0.016 \\
\hline
\end{tabular}

BoNT-A, cohort naive to previous botulinum neurotoxin A interventions; BoNT-A, cohort with a minimum of three previous BoNT-A interventions; $C P$, cerebral palsy; IQR, interquartile range; $T D$, typically developing.

In the BoNT-A cohort, echo-intensity had a positive significant fair association with the number of previous BoNT-A interventions $(r=0.58, p=0.009)$, and a negative non-significant fair association with the frequency between recurrent BoNT-A interventions $(r=-0.41, \quad p=0.078)$. Echo-intensity had a negative significant fair, moderate, and good association with normalized medial gastrocnemius volume in the typically developing, BoNT-A and No-BoNT-A cohorts respectively (Table II, Fig. 2).

Multiple regression analyses revealed that both GMFCS level and BoNT-A intervention history was significantly associated with both echo-intensity (adjusted $r^{2}=0.64$, $p \leq 0.001$, GMFCS level $p \leq 0.001$, BoNT-A history $p \leq 0.001$ ) and normalized medial gastrocnemius volume (adjusted $r^{2}=0.52, p \leq 0.001$, GMFCS level $p \leq 0.001$, BoNT-A history $p=0.003)$.

\section{DISCUSSION}

The first aim of this investigation was to compare normalized medial gastrocnemius volume and echo-intensity between a spastic $\mathrm{CP}$ cohort with a minimum of three recurrent BoNT-A interventions, a spastic $\mathrm{CP}$ cohort naive to BoNT-A interventions, and a typically developing control cohort. The first finding was that the normalized

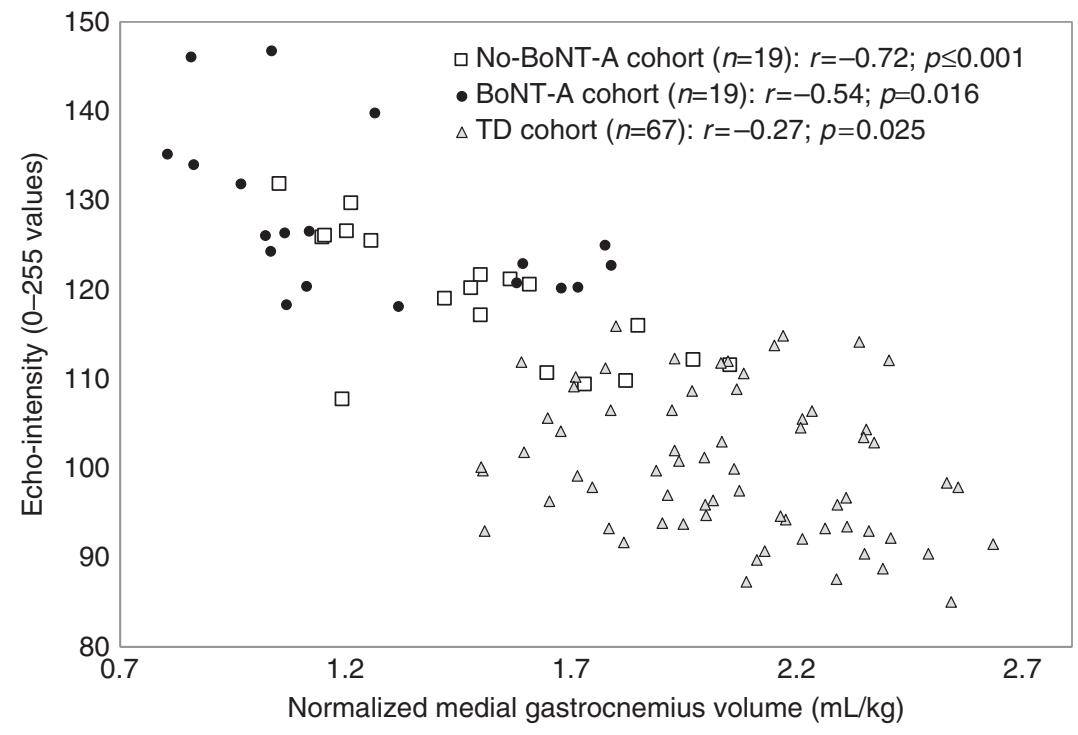

Figure 2: Correlation between medial gastrocnemius echo-intensity and normalized muscle volume. BoNT-A, cohort with a minimum of three previous BoNT-A interventions; No-BoNT-A, cohort naive to previous botulinum neurotoxin A interventions; TD, typically developing control cohort. 
medial gastrocnemius volume of the typically developing cohort was comparable to that of previous reported values in literature, ${ }^{4,5,25}$ and significantly larger than the normalized medial gastrocnemius volumes of both spastic CP cohorts. The spastic CP BoNT-A cohort had the largest deficits in normalized medial gastrocnemius volume, which were also significantly smaller with respect to the NoBoNT-A cohort. Therefore, it may be that the repeated sessions of BoNT-A interventions further inhibit muscle growth, beyond the natural history of the pathology. Similarly, both spastic CP cohorts had significantly higher medial gastrocnemius echo-intensity values compared with the typically developing cohort, with the BoNT-A cohort also presenting with significantly higher echo-intensity values with respect to the No-BoNT-A cohort. Therefore, the first hypothesis, stating that both spastic CP cohorts have smaller normalized volumes and higher echo-intensities with respect to the typically developing cohort, was confirmed. The three-dimensional freehand ultrasonography technique has previously been used to quantify higher medial gastrocnemius echo-intensity values in children with spastic $\mathrm{CP},{ }^{10,20}$ strengthening the concept that not all of the measured muscle volume is functional contractile or connective tissue. This may be due to a higher percentage of intramuscular fat, ${ }^{7,8}$ and changes to the collagen content, such as the extracellular matrix. ${ }^{27}$ It remains to be seen at what age these alterations occur, but the importance of stimulating cross-sectional muscle growth as early as possible is imperative for maximizing long-term muscle function. $^{2}$

The second aim of this investigation was to explore the association between echo-intensity with normalized medial gastrocnemius volume. In all three cohorts, significantly negative associations were found, with the strongest in the No-BoNT-A cohort $(r=0.72)$, followed by the BoNT-A cohort ( $r=0.54)$, and typically developing cohort $(r=0.27)$. Therefore, the second hypothesis, stating that there would be no meaningful association in the typically developing cohort, but strong negative associations in the spastic CP cohorts, was confirmed. The negative association in the typically developing cohort may be explained by attenuation of the ultrasound beam due to the much larger medial gastrocnemius muscles, leading to a reduction in returning echoes. The high association in the No-BoNT-A cohort is very informative as it suggests that alterations to normalized medial gastrocnemius volume and echo-intensity may be explained by the natural history of the pathology, which is likely to be a lack of myofibrillar growth. ${ }^{13}$ However, the weaker association in the BoNT-A cohort infers that something beyond the natural history of the pathology is inducing additional alterations to normalized medial gastrocnemius volume and echo-intensity. This may be explained by BoNT-A interventions targeting an increase in passive ankle joint resistance due to spasticity, when reduced muscle growth and altered tissue properties may have been more culpable. The resulting chemodenervation-induced atrophy, ${ }^{14}$ combined with ankle joint immobilization (serial casting), could have triggered the additional alterations identified in the BoNT-A cohort. Quantifying ankle joint resistance and muscle activation in an objective and quantitative manner, and evaluating the individual influence of both BoNT-A and serial casting, may help to provide more insight into what is happening to the medial gastrocnemius and the ankle joint. ${ }^{2,28,29}$ Smaller medial gastrocnemius volumes are also likely to result in a reduced capacity to generate sufficient active force, but the consequence of higher echo-intensity values is less clear. The understanding of the implications may be supported by earlier research. An increase in passive tissue stiffness of the medial gastrocnemius in spastic CP has been identified, quantified according to the shear wave velocity of ultrasound elastography. ${ }^{27} \mathrm{~A}$ subsequent investigation found that differences in shear wave velocity between the non-paretic and the paretic muscles of individuals with stroke were strongly associated with differences in echo-intensity. ${ }^{27}$ Based on this, higher medial gastrocnemius echo-intensity may be indicative of an increase in passive stiffness of the muscle properties. If so, it would be of great interest to determine whether the medial gastrocnemius is able to increase in length after BoNT-A and serial casting, or whether it is inhibited by the altered tissue composition. Additionally, the ability to recruit and activate motor units is also a known impairment in children and adolescents with spastic CP. ${ }^{1}$ Exploring if higher echointensity values are related to reduced isometric force-generation and rate of force-generation, as seen in sarcopenia populations,${ }^{30}$ would also provide another clinical meaning to higher echo-intensity values in individuals with spastic CP.

The third aim of this investigation was to explore whether in addition to GMFCS level and age, BoNT-A intervention history is significantly associated with alterations in normalized medial gastrocnemius volume and echo-intensity. GMFCS level was included, as it has previously been shown to be associated with medial gastrocnemius volume and echo-intensity, representing the natural history of the spastic CP pathology in the No-BoNT-A cohort. $^{4,8,9,25}$ The multiple regression analyses revealed that both BoNT-A history and GMFCS level significantly associated with both echo-intensity and normalized medial gastrocnemius volume in the combined spastic $\mathrm{CP}$ cohort, thereby confirming the third hypothesis. To the best of our knowledge, this is one of the strongest reported findings of alterations to medial gastrocnemius morphology due to recurrent BoNT-A interventions. This is also supported from a clinical perspective, where it was suggested that the efficacy of BoNT-A interventions to improve overall functional ability in children with spastic CP may diminish after three recurrent treatments. ${ }^{23}$ However, as BoNT-A interventions have been reported to yield functional benefits, at least in the short-term, it would be worthwhile to determine if treatment goals can still be attained with a smaller BoNT-A dosage, perhaps calculated with respect to the normalized medial gastrocnemius volume or echo-intensity, instead of body mass. ${ }^{31}$ 


\section{Limitations}

It is preferable to determine the effects of an intervention using a longitudinal investigation design. However, evaluating the long-term influence of BoNT-A interventions on muscle morphology would span the course of many years, with various feasibility issues. Therefore, this investigation utilized a cross-sectional design, where careful attention was placed on matching two spastic $\mathrm{CP}$ cohorts with differing treatment histories (BoNT-A/No-BoNT-A). Based on the ankle impairments from their earliest clinical examinations, we did not identify any statistically significant differences, aside from slightly less dorsiflexion in the BoNTA cohort, suggesting a reduced muscle growth. However, this may also have been due to insufficient power. Nonetheless, it remains unclear why the treatment histories differed, but it is likely to be related to a more comprehensive evaluation of impairments. This would also include the knee and hip joint levels, the degree of pathological gait, and both patient and family preferences with respect to treatment goals. ${ }^{11}$ Furthermore, as a consequence of the research design, this investigation is unable to delineate between the individual influence of BoNT-A infiltrations and the subsequent protocol of serial casting and physiotherapy. As mentioned earlier, there was a mild attenuation of the ultrasound beam when visualizing the largest medial gastrocnemius muscles in the typically developing cohort. This effect seemed confined to the typically developing cohort, as the largest medial gastrocnemius volume in the spastic CP cohort was around the median of the typically developing cohort. Future investigations may aim to negate this problem by altering the ultrasound time-gain-compensation settings; however, that may introduce new challenges for interparticipant comparisons of echo-intensity. Another possibility is to apply a correction to the ultrasound images that takes into consideration the thickness of the subcutaneous tissue and depth of the muscle. ${ }^{22}$

\section{CONCLUSION}

This investigation identified that a history of three or more BoNT-A interventions may have a negative influence on normalized medial gastrocnemius volume and echo-intensity, beyond the natural history of the spastic CP pathology. This is a novel finding and warrants further confirmation. It may be that BoNT-A interventions are associated with differences seen at the muscle (smaller volume, higher echo-intensity), as we cannot conclude whether they are the cause of the altered muscle properties. However, as a lack of muscle growth and increased passive stiffness seem to be key factors in the presence of joint contractures, it is important to be aware of the potential risks of recurrent BoNT-A interventions in individuals with spastic CP.

\section{ACKNOWLEDGEMENTS}

The authors wish to thank Adam Shortland, Martin Gough, and colleagues from the One Small Step Gait Laboratory, Guy's Hospital, London, UK, and Jaap Harlaar and colleagues from the Vrij University Medical Center, Amsterdam, the Netherlands, for sharing their knowledge and experience in this field of research. The authors are supported by the following funding bodies: Doctoral Scholarships Committee for International Collaboration with non EER-countries (DBOF), KU Leuven, grant number DBOF/12/058; the Flemish Research Foundation (FWO), TAMTA, grant number T005416N; Flemish Research Foundation (FWO), grant number 12R4215N; 'La Fondation Motrice', contract 2016/8. The funders of this investigation had no involvement in the investigation design, data collection, data analysis, manuscript preparation, or publication designs. The authors have stated that they had no interests that might be perceived as posing a conflict or bias.

\section{SUPPORTING INFORMATION}

The following additional material may be found online:

Table SI: Comparisons between the two cohorts of children with spastic cerebral palsy at the time of their earliest clinical examinations

Figure S1: Quantity and timings of the botulinum neurotoxin A interventions.

\section{REFERENCES}

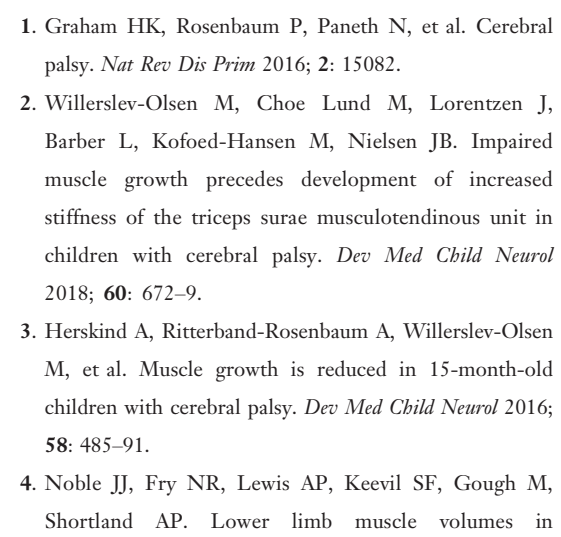

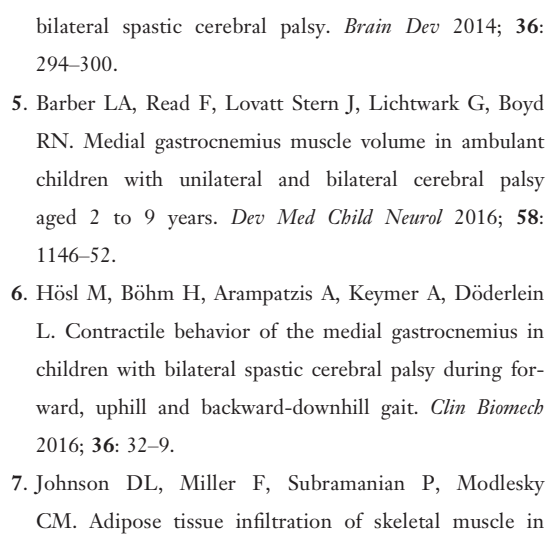

bilateral spastic cerebral palsy. Brain Dev 2014; 36: 294-300.

5. Barber LA, Read F, Lovatt Stern J, Lichtwark G, Boyd RN. Medial gastrocnemius muscle volume in ambulant children with unilateral and bilateral cerebral palsy aged 2 to 9 years. Dev Med Child Neurol 2016; 58: 1146-52.

6. Hösl M, Böhm H, Arampatzis A, Keymer A, Döderlein L. Contractile behavior of the medial gastrocnemius in children with bilateral spastic cerebral palsy during forward, uphill and backward-downhill gait. Clin Biomech 2016; 36: 32-9.

7. Johnson DL, Miller F, Subramanian P, Modlesky $\mathrm{CM}$. Adipose tissue infiltration of skeletal muscle in

children with cerebral palsy. 7 Pediatr 2009; 154: 715-20.

8. Noble JJ, Charles-Edwards GD, Keevil SF, Lewis AP, Gough M, Shortland AP. Intramuscular fat in ambulant young adults with bilateral spastic cerebral palsy. $B M C$ Musculoskelet Disord 2014; 15: 236.

9. Pitcher CA, Elliott CM, Panizzolo FA, Valentine JP, Stannage K, Reid SL. Ultrasound characterization of medial gastrocnemius tissue composition in children with spastic cerebral palsy. Muscle Nerve 2015; 52: 397-403.

10. Obst SJ, Boyd R, Read F, Barber L. Quantitative 3-D ultrasound of the medial gastrocnemius muscle in children with unilateral spastic cerebral palsy. Ultrasound Med Biol 2017; 43: 2814-23. 
11. Gage JR, Schwartz MH, Koop SE, Novacheck TF. The Identification and Treatment of Gait Problems in Cerebral Palsy. London: Mac Keith Press, 2009.

12. Nieuwenhuys A, Papageorgiou E, Pataky T, De Laet T, Molenaers G, Desloovere K. Literature Review and comparison of two statistical methods to evaluate the effect of botulinum toxin treatment on gait in children with cerebral palsy. PLoS One 2016; 11: e0152697.

13. Gough M, Shortland AP. Could muscle deformity in children with spastic cerebral palsy be related to an impairment of muscle growth and altered adaptation? Dev Med Child Neurol 2012; 54: 495-9.

14. Williams SA, Reid S, Elliott C, Shipman P, Valentine J. Muscle volume alterations in spastic muscles immediately following botulinum toxin type-A treatment in children with cerebral palsy. Dev Med Child Neurol 2013; 55: 813-20.

15. Williams SA, Elliott C, Valentine J, Gubbay A, Shipman $\mathrm{P}$, Reid S. Combining strength training and botulinum neurotoxin intervention in children with cerebral palsy: the impact on muscle morphology and strength. Disabil Rebabil 2013; 35: 596-605.

16. Barber L, Hastings-Ison T, Baker R, Kerr Graham H, Barrett R, Lichtwark G. The effects of botulinum toxin injection frequency on calf muscle growth in young children with spastic cerebral palsy: a 12 -month prospective study. 7 Child Orthop 2013; 7: 425-33.

17. Valentine J, Stannage K, Fabian V, et al. Muscle histopathology in children with spastic cerebral palsy receiving botulinum toxin type A. Muscle Nerve 2016; 53 : 407-14.

18. Cenni F, Monari D, Desloovere K, Aertbeliën E, Schless SH, Bruyninckx H. The reliability and validity of a clinical 3D freehand ultrasound system. Comput Methods Programs Biomed 2016; 136: 179-87.

19. Fry NR, Gough M, Shortland AP. Three-dimensional realisation of muscle morphology and architecture using ultrasound. Gait Posture 2004; 20: 177-82.

20. Cenni F, Schless SH, Bar-On L, et al. Reliability of a clinical 3D freehand ultrasound technique: analyses on healthy and pathological muscles. Comput Methods Programs Biomed 2018; 156: 97-103.

21. Pillen S, Tak RO, Zwarts MJ, et al. Skeletal muscle ultrasound: correlation between fibrous tissue and echo intensity. Ultrasound Med Biol 2009; 35: 443-6.

22. Young HJ, Jenkins NT, Zhao Q, Mccully KK. Measurement of intramuscular fat by muscle echo intensity. Muscle Nerve 2015; 52: 963-71.

23. Molenaers G, Fagard K, Van Campenhout A, Desloovere K. Botulinum toxin A treatment of the lower extremities in children with cerebral palsy. 7 Child Orthop 2013; 7: 383-7.

24. Pillen S, Van Dijk JP, Weijers G, Raijmann W, De Korte CL, Zwarts MJ. Quantitative gray-scale analysis in skeletal muscle ultrasound: A comparison study of two ultrasound devices. Muscle and Nerve 2009; 39: 781-6.

25. Schless SH, Hanssen B, Cenni F, et al. Estimating medial gastrocnemius muscle volume in children with spastic cerebral palsy: a cross-sectional investigation. Dev Med Child Neurol 2018; 60: 81-7.

26. Altman DG. Practical Statistics for Medical Research. London: Chapman and Hall, 1991.

27. Lieber RL, Roberts TJ, Blemker SS, Lee SSM, Herzog W. Skeletal muscle mechanics, energetics and plasticity. 7 Neuroeng Rebabil 2017; 14: 108.

28. van den Noort JC, Bar-On L, Aertbeliën E, et al. European consensus on the concepts and measurement of the pathophysiological neuromuscular responses to passive muscle stretch. Eur 7 Neurol 2017; 24: 981-e38.

29. Bar-On L, Van Campenhout A, Desloovere K, et al. Is an instrumented spasticity assessment an improvement over clinical spasticity scales in assessing and predicting the response to integrated botulinum toxin type a treatment in children with cerebral palsy? Arch Phys Med Rehabil 2014; 95: 515-23.

30. Gerstner GR, Thompson BJ, Rosenberg JG, Sobolewski EJ, Scharville MJ, Ryan ED. Neural and muscular contributions to the age-related reductions in rapid strength. Med Sci Sports Exerc 2017; 49: 1331-9.

31. Picelli A, Bonetti P, Fontana C, et al. Is spastic muscle echo intensity related to the response to botulinum toxin type a in patients with stroke? A cohort study. Arch Phys Med Rebabil 2012; 93: 1253-8.

\section{Mec Keith Press}

\section{Practical Guide}

\section{The Management of ADHD in Children and Young People}

\section{Edited by Val Harpin}

- The only ADHD guide to include input from paediatricians, child and adolescent psychiatrists and psychologists, and specialist nursing teams

- Examines comorbid/coexisting difficulties and how they affect management

- Discusses ADHD and substance misuse

- Describes how to support young people in transition to adult services

Contact us at admin@mackeith.co.uk to receive further details.

January 2017 / 240 x 170mm / 256 pp / Softback / ISBN 978-1-909962-72-9 / £34.95

\section{www.mackeith.co.uk/shop}




\section{RESUMEN}

VOLUMEN DEL MÚSCULO GASTROCNEMIUS MEDIAL E INTENSIDAD DE LA ECOGRAFÍA DESPUÉS DE LA COLOCACIÓN DE NEUROTOXINA BOTULÍNICA (TIPO A), EN NIÑOS CON PARÁLISIS CEREBRAL ESPÁSTICA (PC)

OBJETIVO Esta investigación de corte transversal evaluó si la colocación recurrente de neurotoxina botulínica tipo A (BoNT-A) en el músculo gastrocnemius medial tienen una influencia en la morfología muscular, más allá del nivel del Sistema de Clasificación de la Función Motora Gruesa (GMFCS, siglas en ingles).

MÉTODO Una cohorte de niños con desarrollo tipico ( $n=67 ; 43$ varones, 24 mujeres; mediana de edad 9 años 11 meses [rango 7 años 10 meses -11 años 6 meses]), otra cohorte de niños con parálisis cerebral espástica (PC) que no habían recibido intervenciones de BoNT-A ( $n=19 ; 10$ hombres, nueve mujeres; mediana de edad 9 años 3 meses [rango 8 años 5 meses -10 años 10 meses]) y una cohorte de niños con PC espástica con un mínimo de tres administraciones recurrentes de BoNT-A en el músculo gastrocnemius medial (BoNT-A; $n=19 ; 13$ varones, seis mujeres; mediana de edad 9 años 8 meses [rango 7 años 3 meses - 10 años 7 meses]) fueron reclutados. Se usó ultrasonido tridimensional a mano alzada para estimar el volumen del músculo gastrocnemius medial normalizado a la masa corporal y la intensidad del eco.

RESULTADOS El volumen del músculo gastrocnemius medial normalizado y la intensidad del eco difirieron significativamente entre las dos cohortes de PC espástica $(p \leq 0,05)$, la cohorte BoNT-A tuvo alteraciones mayores. Las asociaciones entre el volumen músculo gastrocnemius medial normalizado y la intensidad del eco fueron más altas en la cohorte No-BoNT-A, seguidas de la cohorte BoNT-A. Los análisis de regresión múltiple revelaron que tanto el nivel de GMFCS como el antecedente de intervención de BoNT-A se asociaron significativamente con un volumen del músculo gastrocnemius medial normalizado más pequeño y una mayor intensidad de eco.

INTERPRETACIÓN La colocación recurrentes de BoNT-A pueden inducir alteraciones en el volumen del músculo gastrocnemius medial y en la intensidad del eco más allá de la historia natural de la patología por PC espástica.

\section{RESUMO}

\section{VOLUME E ECO-INTENSIDADE DO MÚSCULO GASTROCNÊMIO MEDIAL APÓS INTERVENÇÕES COM NEUROTOXINA BOTULÍNICA A EM CRIANÇAS COM PARALISIA CEREBRAL ESPÁSTICA}

OBJETIVO Esta investigação transversal avaliou se intervenções recorrentes com neurotoxina botulínica A (NTBo-A) no músculo gastrocnêmio medial têm influência na morfologia muscular, além do nível segundo o Sistema de Classificação da Função Motora Grossa (GMFCS).

MÉTODO Uma coorte de crianças com desenvolvimento típico ( $n=67 ; 43$ do sexo masculino, 24 do sexo feminino; idade mediana 9a $11 \mathrm{~m}$ [variação $7 \mathrm{a} 10 \mathrm{~m}-11$ a $6 \mathrm{~m}$ ]), uma coorte de crianças com paralisia cerebral espástica (PC) que nunca recebeu intervenções com NTBo-A (No-NTBo-A; $n=19 ; 10$ do sexo masculino, nove do sexo feminino; idade mediana 9a 3m [variação 8a 5m-10a 10m]) e uma coorte de crianças com PC espástica com no mínimo três intervenções de NTBo-A no músculo gastrocnêmio medial (NTBo-A; $n=19 ; 13$ do sexo mascuino, seis do sexo feminino; idade mediana 9a $8 \mathrm{~m}$ [variação 7 a $3 \mathrm{~m}-10 \mathrm{a} 7 \mathrm{~m}$ ]) foram recrutadas. Ultrassom tridimensional foi usado para estimar o volume do gastrocnêmio normalizado para a massa corporal e eco-intensidade. RESULTADOS O volume normalizado e eco-intensidade do músculo gastrocnêmio medial diferiu significantemente entre as duas coortes de PC espástica $(p \leq 0,05)$, com a coorte NTBo-A tendo maiores alteracões. Associações entre o volume normalizado do gastrocnêmio e eco-intensidade foram maiores na coorte No-NTBo-A, seguida pela coorte NTBo-A. Análises de regressão múltipla revelaram que tanto o nível GMFCS quanto a história de intervenção com NTBo-A foram significativamente associadas com menor volume normalizado do músculo gastrocnêmio medial e maior eco-intensidade.

INTERPRETAÇÃO Intervenções recorrentes com NTBo-A podem induzir alterações no volume e eco-intensidade do músculo gastrocnêmio medial, além da história natural da patologia da PC espástica. 